\title{
Significance of Artificial Island in Overcoming the Scarcity of Land due to Global Warming and Sea-Level Rise
}

\author{
Needa Javed \\ Department of Architecture \& Interior Design, University of Bahrain, Tubli 00973, Bahrain
}

Received: March 06, 2017 / Accepted: March 20, 2017 / Published: June 30, 2017.

\begin{abstract}
This paper highlights the idea of constructing a building or group of buildings partially in the water. It attempts to describe the futuristic proposal of constructing on water due to scarcity of land and decreasing of lands due to global warming issues and the resulted sea level rise, also the consequences of making artificial (man-made) islands that are in direct connection to Bahrain Island. This report briefly examines the theoretical roots of the proposal including basic criteria and architectural aspects of structure within water body that could satisfy the human needs.
\end{abstract}

Key words: Building on water, artificial islands, comparison, structure, architectural aspect.

\section{Introduction}

\subsection{Inspiration of the Project}

Bahrain has limited land area which leads to having urban developing projects due to the needs for future urban lands. The inspiration of the project comes from the growing trend of reclamation of the land and the fact that by reclaiming the land we are faced by many social and economical problems [1] consequently, this reclamation damages and destroys the marine live and deteriorates the ecology within the water body surrounding Bahrain. So as a proposal serving as a solution to these problems a partially underwater building would save the extra cost of reclaiming the land, provide a connection with the sea for people of Bahrain that was their original trait in the past and it also would attract tourists and investors because the recreational facilities are installed and certain social issues are solved like over population, unemployment and ability to explore new ideas and technology in terms of architecture and structure.

Corresponding author: Needa Javed, B.S.c architecture, research field: urban sustainability.

\subsection{Need of the Project}

"Due to a lot of land reclamation in Bahrain and less coastal areas to be built around and the threat of sea level rise, this project provides an alternative for land reclamation with constructing in the water that could reduce the environmental effects due to land reclamation to minimum." As we know three quarters of the earth is made up of water yet humans decide to live on land and overpopulate it. Within human developing projects, many industrial projects have the same consequence because of environmental pollutions in many types which cause global warming phenomena and many issues. The idea of creating partially underwater city within sustainable project will not only help solve the over population and urban coastal land scarcity in Bahrain at the same time with its technology it will provide a sustainable living/recreational environment.

\subsection{Effects of Global Warming \& SLR (Sea Level Rise) Worldwide}

It is a fact widely known that global warming is an ever-present and immediate threat that is facing the 
modern developing world. It is directly related to a rise in sea level, human activities i.e., carbon emissions caused by careless industrialization and pollution caused by combustible engines, which are the main contributors in an increase in earth's temperature as $\mathrm{CO}_{2}$ is a kind of greenhouse gas which is then trapped by earth's atmosphere that rises the temperature of earth causing the melting of ice-caps and glaciers which in turn give a rise to the sea-level. Human activities (carbon emissions) get trapped in the earth's atmosphere, this heat that is absorbed by the earth surfaces, increases the water temperature in oceans beds and sea, causing liquid water expands and in turn increases the sea level. Also the rise in the temperature of earth causes the ice caps to melt (in-land + sea ice). While the sea-ice is not a contributing factor to SLR, in-land, ice-caps and their melting is a direct contributor to sea-level rise.

\subsection{Effects of SLR in Various Regions}

According to an estimate for every 0.3 meters rise in sea-level, above 90 meters of cultivable and live able land will be reclaimed by the sea. The following countries will be highly affected by the rise in sea levels, as shown in Figs. 1 and 2.

Asia:

Bangladesh and Indonesia are estimated to be the most severely affected countries in the continent of Asia with lives of millions at stake.

\section{Europe:}

Italy, UK, Turkey are among the highest to face the consequences as a result of SLR.

\section{North \& South America:}

San Francisco, Florida, Miami, San Diego, New Orleans, New York coastal areas are expected to be at severe risk.

\section{Australia:}

Gold coast will be highly affected by sea level rise. Africa:

Lagos, Mogadishu, Tunis, Monrovia, Mombasa are among few of many that will be under the effects of global warming.

Asia, being one of the rapidly developing continents, is faced with the threat of climatic change along with environmental and energy issues. Along with the continents growth of the sea level, temperature and greenhouse gas emissions are also growing thus increasing more risks to natural disasters and affecting lives of millions of people in Asia. The following picture shows that all the Asian countries are affected by climatic change in one way or another.

The overall population of Asia is about $60 \%$ of total world population among which China and India's population accounts for a total of $40 \%$. Climatic change is not just environmental rather it affects the energy, food, land and water resources as well. As described earlier global warming is directly related to human activities. According to the report of the UN convention to combat desertification, temperatures are expected to increase more rapidly in northern areas of Pakistan, India \& western China. Overall, the temperature in the region is expected to increase by $0.5-2{ }^{\circ} \mathrm{C}$ by 2030 and $1-7^{\circ} \mathrm{C}$ by 2070 .

In general, the effects of global warming and climate change can be schematically represented as follows.

Fig. 3 shows the consequences due to climate change and increase in the temperature and sea-level. As sea-level rises, land scarcity increases as more and more cultivable and live able land is reclaimed by the sea. Also due to a rise in sea-level, salinity increases in the ground water table making it impossible to use the affected land for agricultural purposes, which causes a major scarcity of food as population increases. Due to increase in population and decline in the cultivable/livable land, there is an increase in internal migration, as people start to move from problematic area towards other areas and as the newer better areas are already over-populated, this unsuccessful internal migration turns into external migration, where people illegally try to migrate to other countries via porous in-land borders. This can cause a problem for the receiving country, where this illegal migration can 


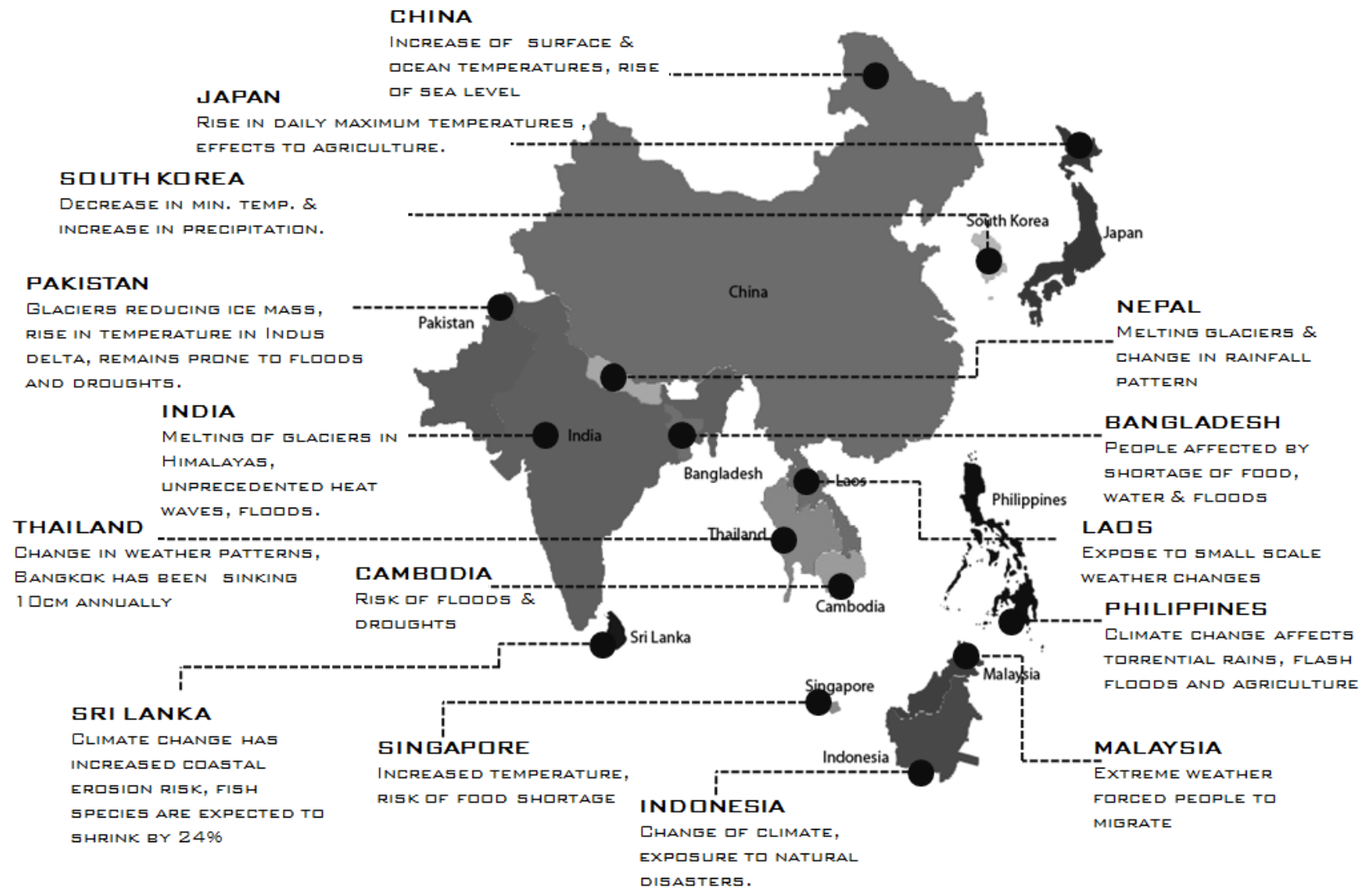

Fig. 1 Effects of SLR on Asian countries.

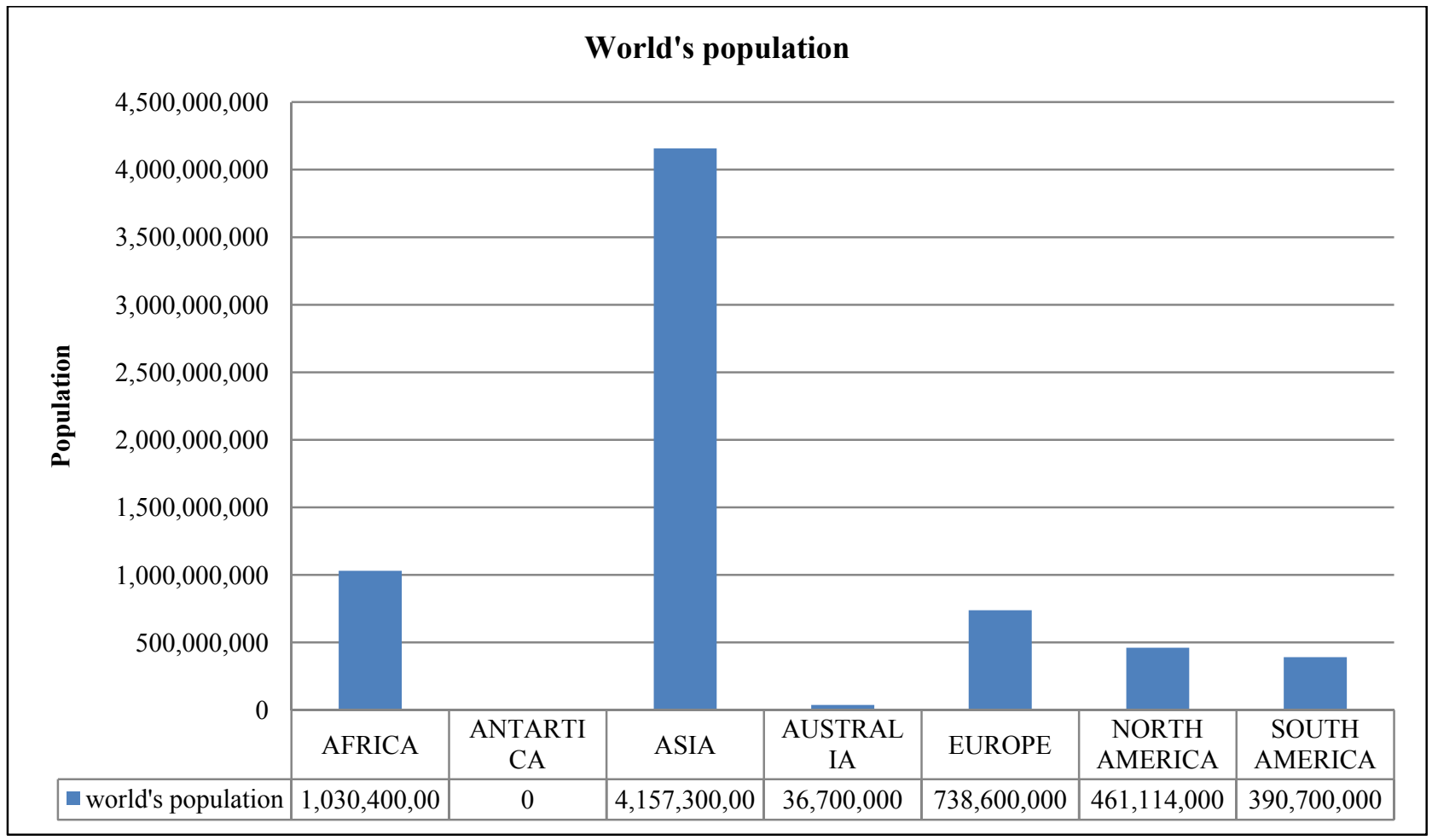

Fig. 2 World's population chart. 


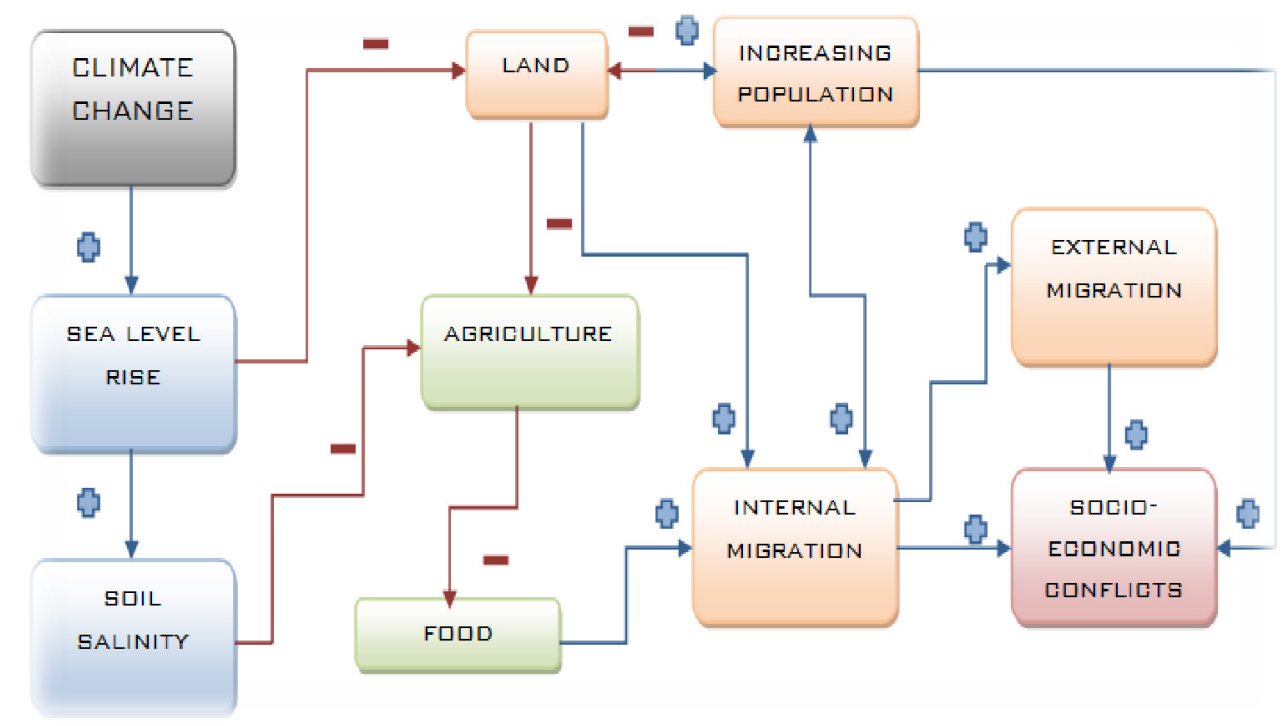

Fig. 3 Consequences of climatic change.

cause socio-economic problems along side health issue and a drain on natural resources as well as security issues.

\subsection{Theoretical Background of Artificial Islands}

Many researchers have conducted researches on the creation of the artificial islands. Some of them solely focused on the environmental impacts of it. For example, Butler [2] wrote in an article "The Price of the World: Dubai's Artificial Future" that the artificial islands created in Dubai are resulting in the creation of water that is filled with silt. Moreover, the increase in the sediment particles has choked the reef and disturbed the natural water currents. In response to his article, the environmental scientist from Dubai said that the artificial islands offer more protection and have even enhanced the fauna of the sea. In addition to that, they have also recorded the presence of diverse marine organisms. Salahuddin [3] says that the construction of such islands has buried and suffocated wildlife, increased turbidity and changed the alongshore sediment transport. But these researches solely focus on the environmental aspects of these islands. There are, however, studies performed to analyze the impact of the reclaimed lands on the society itself. Reclamation of land has been practiced worldwide and was created to either serve the demands of growing population or to provide land for irrigation and industries to boost the economy. In China it is referred as a "gift from the sea" [4] the impacts of these islands in Egyptian society show that these islands were mainly inhabited in hope for a better life. However, the settlers faced various challenges of lacking a sense of belonging due to lack of services and infrastructure, for instance absence of secondary schooling resulted in the families to split. People felt a sense of being abandoned by the Government. However, there were some people who enjoyed living in the reclaimed land and believed to have established stronger connections with the community. For instance, women who were bound by the rules and social norms of the village were able to negotiate those principles and participate in shaping the society. They had more freedom and were away from the social control of their families [5]. Moreover, the reclamation of land has been elevated to a very high level and has become a mark of development of a country. This is due to the obvious influence of the artificial islands of the Middle East. In the Middle East, they represent the powerful societal forces and the possession of urban spaces for elite interest. The creation of such islands reduces the potentials for an urban public space and limits the horizon for the 
development of more socially just future cities. In addition to that these reclaimed lands create privatization, exclusion and hyper-inequality in the society, most of these islands are designed as residential spaces or holiday spots. They are admitted to people on the basis of wealth. Each aspect of the island is designed to serve the elites and to segregate their services and spaces from the normal citizens [6].

Land reclamation in GCC was first carried out by Dubai and this trend then spread in the entire gulf. Artificial or man-made islands are the places that are created by people to meet certain needs or desires. They are artificially created and do not exist before in the nature. It is not a new phenomenon but has been practiced since ancient times. There are many examples such as the Palm Jumeraih in Dubai, the palm Jebel Ali, etc.

The process of reclamation has influenced the urban development of Bahrain as well (Fig. 4). Bahrain is surrounded by water from all the sides. It's an island enclosed by the Arabian Gulf Sea. Global warming is an increasing threat where water is increasing with the risk of sinking soil around its perimeter each year. A solution that has been adapted by many engineers in order to overcome the land scarcity issue is the construction of artificial islands or in other words "land reclamation". The term "land reclamation" means land fill by creating new land from the sea or river bed [7].

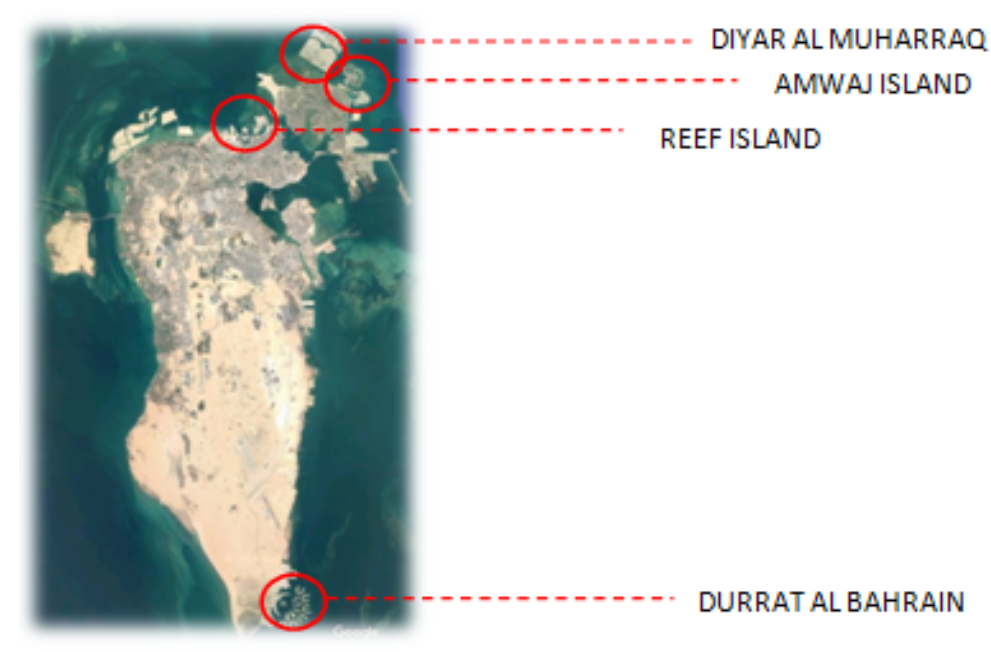

Fig. 4 Manmade islands in Bahrain.
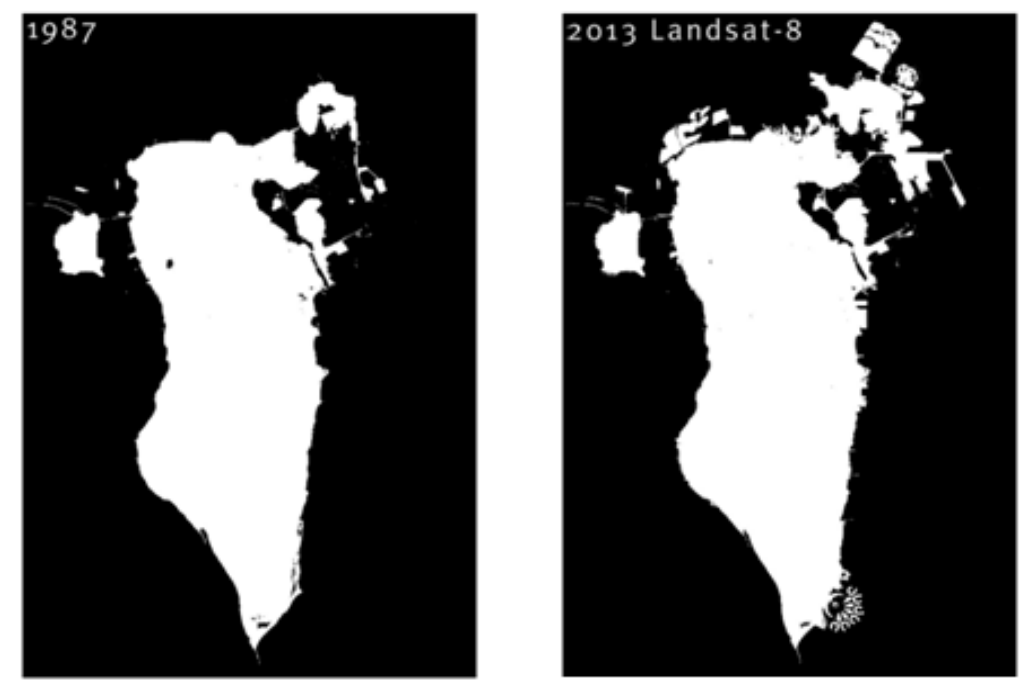

Fig. 5 Island expansion between 1987-2013. 


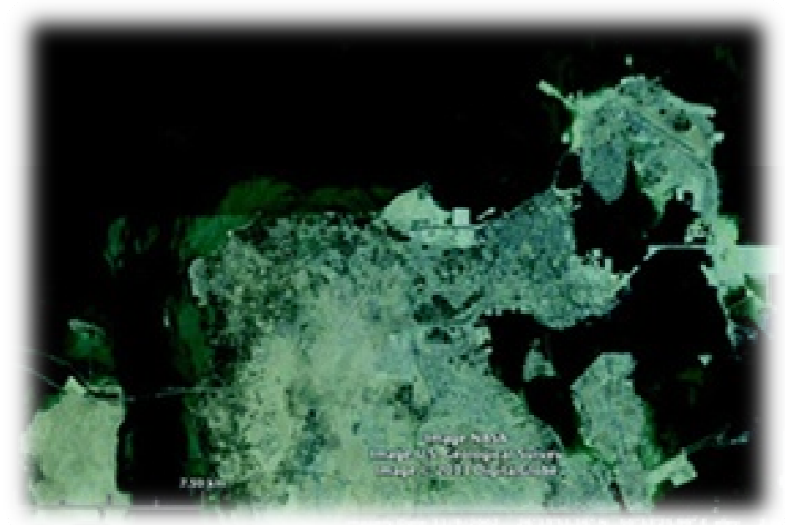

Fig. 6 The increased land of Muharraq.

Specifically in Bahrain we are faced with the challenge of rapid urban growth, Bahrain in a very short time has taken features of the modern nation; significant change in social and family life is evident and continues to create social and economical problems [9]. In order to solve these problems and step towards modernism perhaps, there is an increasing trend of constructing artificial islands throughout the Middle East and in Bahrain as well. In point of fact, Bahrain, with its relatively small land area, is one of the countries with the highest proportion of reclaimed land-area in the world, with land area estimated to have increased from $650 \mathrm{~km}^{2}$ to $731 \mathrm{~km}^{2}$ between 1987 and 2013 [10]. It's clear from Fig. 5 that land reclamation was extended for a period of next 7 years and by 2013 about $50 \mathrm{~km}^{2}$ of more land was introduced to the island. Hence the total land area was increased up to $730.8 \mathrm{~km}^{2}$, and most of the land was added in the northern part of the kingdom. "The approximately $10 \mathrm{~km}^{2}$ of land reclaimed between 1987 and 1998 were primarily added to al-Muharraq Island in the North East. Between 2004 and 2013, however, multiple large-scale land reclamation projects had occurred. Substantial land was added to Muharraq Island as well as the northern coast of al-Awal Island. In addition, a set of fish and crescent shaped islands was added in the south." [11].

Smaller developments have also been built in the financial area of Manama, the capital, including Bahrain Bay, Reef Island, and the Bahrain Financial

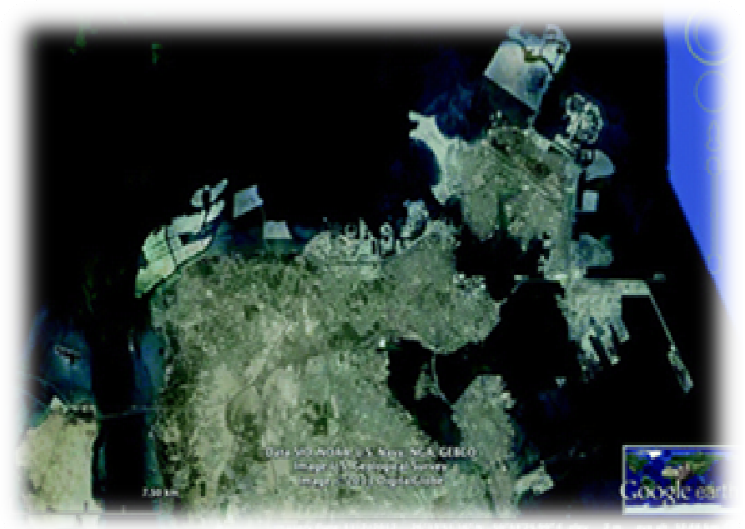

Harbor. A development located in Bahrain's southern tip, Durrat Al Bahrain, is also approaching completion and consists of six atolls and five pearl-shaped islands spread over twenty-one square kilometers. A recent study using topographical and aerial photographs found that Bahrain's second-largest island of Muharraq had quadrupled in size since 1950, with the majority of new land having been reclaimed during the past fifteen years as shown above (Fig. 6) [12] as well as $90 \%$ of reclamation is currently going on in Bahrain [1].

\section{Solving Land Scarcity Problem with Land Reclamation}

Due to the Economic advantage that is presented by Coastal Areas, it is a common trend for Coastal Areas to be more prosperous and hence more developed especially in the region of Kingdom of Bahrain. The offer of a better life style is a constant attraction for skilled and population to move to the Coastal Areas. This inevitably causes a shortage of living space in the coastal areas as population increases. Additionally, the sea-level rise also affects the already limited land making the margin for future development in these areas narrower and narrower. Reclaiming land from sea and building artificial islands in not only more cost-effective, it can also be used as a barrier/security measure against constant rise in sea-level and its effects on the coastal area, e.g., land reclamation in Jakarta, where 17 artificial islands are being built in lieu of securing their coastal areas from the threat of floods 
and typhoons caused by the dramatic change in the climate conditions. In Singapore, stone break water are being enlarged in order to protect the low-lying coastal areas from SLR. In New Orleans, a sea-wall is being built in order to protect the coastal areas from typhoons devastation caused by Hurricane Katrina.

\section{Results and Discussions}

3.1 Cost Effectiveness of Land Reclamation versus Improvement of Pre-existing Infrastructure in the Coastal Areas

Though land reclamation is expensive, it can only be effective if it raises the height of the coastal area in order to cope with the rising sea levels. According to an estimate, even if land-reclamation is costly, it is still 10 times less expensive than raising the ground level of an already existing infrastructure and will still be more effective against natural disasters. Standard of infrastructure planning can also be improved in newly built/reclaimed areas with special fore-thought given the technical and environmental factors.

\subsection{How Present Method of Land Reclamation can Be} Improved in Order to Reduce More and More Environmental Drawbacks

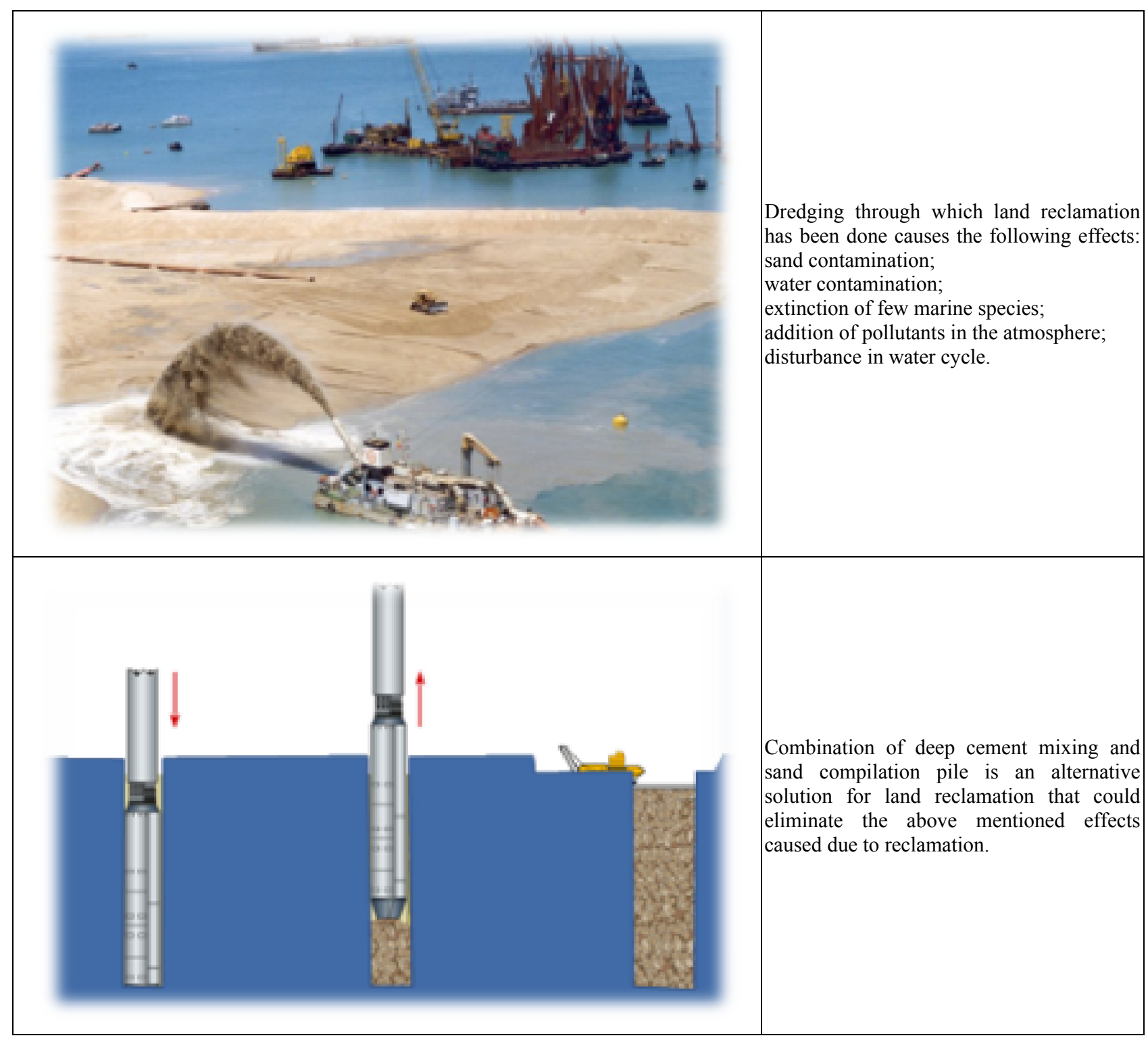




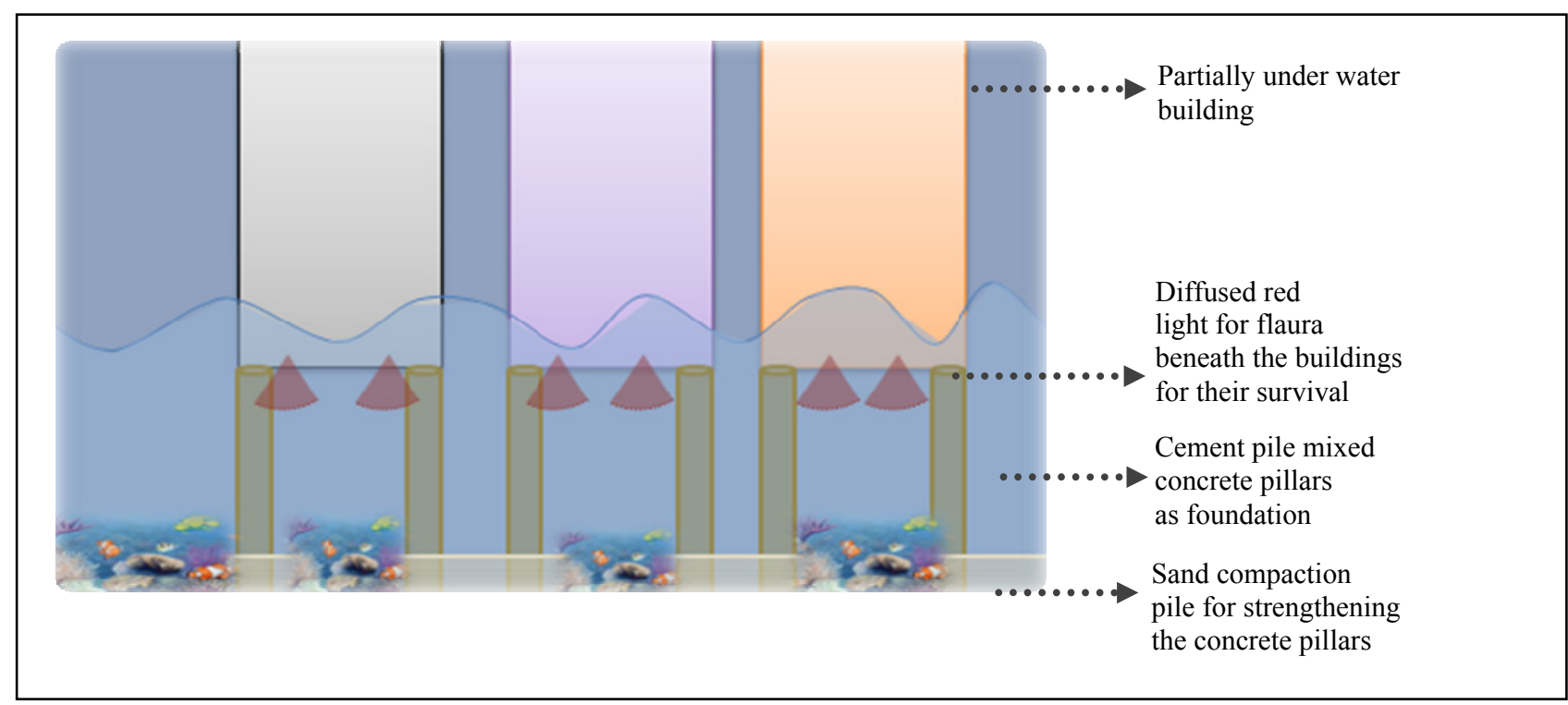

\section{Conclusions}

It seems strange that after so many provided proofs and facts adding up in favor of the existence of global warming, sea level rise and threats related to them, many still deny its existence. But as human race develops and steps into a hopefully more enlightened future, perhaps going to the very roots of our genetic programming is just as important as it always has been. Survival and preservation of the species, global warming and sea level rise are paramount issues facing the whole of world's population and technically sound and cost-effective, land reclamation seems to be a prominent solution to these problems which can ensure safety and betterment of the long-term future.

\section{References}

[1] Habib Toumi, B. B. 2010. "Gulf News." Retrieved September $\quad$ Friday, $2016 . \quad$ From http://gulfnews.com/news/gulf/bahrain/bahrain-parliamen t-wants-solution-to-land-reclamation-issue-1.567052.

[2] Butler, T. 2005. "Mongabay." Retrieved October Wednesday, $2016 . \quad$ From https://news.mongabay.com/2005/08/dubais-artificial-isla nds-have-high-environmental-cost/.

[3] Salahuddin, B. 2006. "Tecnico Lisboa." Retrieved October Tuesday, 2016. From https://fenix.tecnico.ulisboa.pt/downloadFile/3779578854 207/The $\% 20$ Marine $\% 20$ Environmental\%20Impacts $\% 20$ o f\%20Artificial\%20Island\%20Construction.pdf.
[4] Shepard, W. 2015. "The Gift from the Sea." In Through Land Reclamation, China Keeps Growing and Growing, edited by Shepard, W. Retrieved September Sunday, 2016. From City Metric: http://www.citymetric.com/skylines/ gift-sea-through-land-reclamation-china-keeps-growing-a nd-growing-1350.

[5] Adriansen, H. K. 2007. "Land Reclamation in Egypt: A Study of Life in the New Lands." Elsevier-Geoforum 40 (2009): 11.

[6] Grydehoj, A. 2015. "Making Ground, Losing Space: Land Reclamation and Urban Public Space in Island Cities." Island dynamics 1 (1): 179.

[7] Wikipedia. 2016. Wikipedia the Free Encyclopedia. Retrieved October Tuesday, 2016. From https://en.wikipedia.org/wiki/Land_reclamation.

[8] 2015. "Bahrain Economic Development Board." Retrieved December Friday, 2016. From http://www.bahrainedb.com/_layouts/National-developm ent-strategy/en/document $/ \# \mathrm{p}=1$.

[9] Jeffrey B., and Nugent, T. H. 1985. Bahrain and the Gulf: Past, Perspectives and Alternative Futures. 2nd ed., edited by Jeffrey, T. H., and Nugent, B. London \& Newyork: Routledge.

[10] Bahrain, C. F. 2015. "First for Bahrain: First Artificial Islands." Retrieved October Saturday, 2016. From http://www.citizensforbahrain.com/index.php/entry/first-f or-bahrain-first-artificial-islands.

[11] Susan Wolfinbarger, J. D. 2014. “Advancing Science Serving Society.” Retrieved October Tuedsay, 2016. From https://www.aaas.org/page/investigating-land-use-and-lan d-cover-change-bahrain-1987-2013.

[12] Fakhro, E. 2013. "Land Reclamation in the Arabian Gulf: Security, Environment, and Legal Issues." Journal of Arabian Studies 3 (1): 36-52. 